\title{
Divórcio, fim ou recomeço? Avaliações e percepções frente às Oficinas de Parentalidade
}

\section{Divorce, end or restart? Evaluations and perceptions above the Parenthood Workshops}

\author{
Liniker Douglas Lopes da Silva ${ }^{1}$, Luciana Maria da Silva ${ }^{2}$
}

\begin{abstract}
Resumo
No decorrer dos processos de divórcio/dissolução conjugal, os genitores podem apresentar dificuldades em dissociar parentalidade de conjugalidade, envolvendo os filhos em seus embates, o que pode ser prejudicial ao desenvolvimento das crianças e adolescentes. Pensando nisso, em 8 de maio de 2014 o Conselho Nacional de Justiça (CNJ), por meio da Recomendação 050/14, orientou aos tribunais do País a adotarem as Oficinas de Parentalidade como política pública de resolução e prevenção de conflitos familiares. Nesse sentido, o presente trabalho objetiva verificar as avaliações e percepções imediatas dos genitores que participaram das Oficinas de Parentalidade em um município do Triângulo Mineiro (Minas Gerais, Brasil). Trata-se de um estudo de corte transversal amparado na abordagem mista de pesquisa que contou com a participação de 78 genitores. Dados quantitativos foram descritos em porcentagens e qualitativos foram analisados via técnica de análise de conteúdo. Os resultados evidenciaram que, na opinião dos genitores, as Oficinas de Parentalidade constituíram-se como um importante espaço de reflexão, auxiliando-os a melhorar suas relações familiares, ainda que o conflito conjugal e a culpabilização do ex-parceiro continue preponderando para alguns participantes. Enquanto uma política pública as Oficinas de Parentalidade demostram que o divórcio não significa o fim das relações familiares, mas sim um recomeço.
\end{abstract}

Palavras-chave: Divórcio. Parentalidade. Relações familiares. Relações pais-filho.

\begin{abstract}
In the course of divorce/marital dissolution processes, parents may experience difficulties in dissociating parenthood from conjugality, involving children in their conflicts, which can be detrimental to the development of children and adolescents. With that in mind, on May 8, 2014, the National Council of Justice (CNJ), through Recommendation 050/14, instructed the country's courts to adopt Parenting Workshops as a public policy for resolving and preventing family conflicts. In this sense, the present work aims to verify the immediate evaluations and perceptions of the parents who participated in the Parenting Workshops in a city in the Triângulo Mineiro (Minas Gerais, Brazil). This is a cross-sectional study supported by the mixed research approach that involved the participation of 78 parents. Quantitative data were described in percentages and qualitative data were
\end{abstract}

\footnotetext{
${ }^{1}$ Doutorando em Psicologia na Universidade de São Paulo (USP), Ribeirão Preto, São Paulo, Brasil. Professor do Departamento de Psicologia da Universidade de Uberaba (Uniube), Uberaba, Minas Gerais, Brasil. E-mail: linikerlopes@usp.br

${ }^{2}$ Doutorado em Psicobiologia pela Universidade de São Paulo (USP), Ribeirão Preto, São Paulo, Brasil. Professora do Departamento de Saúde Coletiva da Universidade Federal do Triângulo Mineiro (UFTM), Uberaba, Minas Gerais, Brasil. E-mail: lumarias@hotmail.com
} 
analyzed using the content analysis technique. The results showed that, in the opinion of the parents, the Parenting Workshops constituted an important space for reflection, helping them to improve their family relationships, even though the marital conflict and the blaming of the ex-partner continue to predominate for some participants. As a public policy, the Parenting Workshops demonstrate that divorce does not mean the end of family relationships, but a new beginning.

Keywords: Divorce. Parenting. Family relations. Parent-child relations.

\section{Introdução}

A palavra "divórcio" vem do latim divortium, que quer dizer "separação", que por sua vez é derivada de divertere, que significa "tomar caminhos opostos, afastar-se". Em meio a estas significações, entende-se a dissolução conjugal como um processo que ocorre no ciclo vital da família e que desafia sua organização e dinâmica relacional. O divórcio foi regulamentado judicialmente no Brasil em 1977, evidenciando configurações familiares que já se faziam presentes, de modo velado, em nossa sociedade (CANO et al., 2009). Nas últimas décadas, o número de processos de divórcio/ dissolução conjugal vem crescendo consideravelmente em nosso País e tende a aumentar no decorrer dos anos (BRITO; SILVA, 2017).

O elevado número de divórcios na contemporaneidade relaciona-se às transformações sociais e traz à baila novas formas de pensar e repensar famílias e suas relações que paulatinamente vêm sofrendo alterações, tanto em termos estruturais quanto nas funções desempenhadas por seus membros (SILVA, CHAPADEIRO; ASSUMPÇÃO, 2019). Minuchin, Colapinto e Minuchin (1999) entendem a família como um sistema aberto no qual os membros se relacionam entre si e com o ambiente, estabelecendo uma dinâmica relacional, na qual desempenham determinados papéis na busca da estabilidade do sistema familiar. Em meio à dinâmica relacional, os membros da família enfrentam as contradições de seus comportamentos, afetos, tensões e os conflitos que permeiam o ambiente e que, de maneira concomitante, contribuem para que o sistema se mantenha dinâmico e em contínua transformação.

De acordo com a abordagem sistêmica, todos os componentes da família são interdependentes ou subsistemas, ou seja, cada membro está interligado, fazendo com que a mudança de um acarrete mudanças nos outros. Assim, a vivência da dissolução conjugal afetará não somente o casal, mas sim, todos os que fazem parte do sistema familiar, inclusive as crianças e adolescentes, podendo gerar tanto afastamentos, quanto aproximações entre pais e filhos, a depender da dinâmica estabelecida pelo ex-casal e da maneira como administram seus conflitos (JURAS; COSTA, 2018; MENDES et al., 2016; MINUCHIN; COLAPINTO; MINUCHIN, 2011; OLIVEIRA; CREPALDI, 2018; SILVA; CHAPADEIRO, 2019).

Enquanto um complexo fenômeno que pode acometer o sistema familiar, o divórcio/dissolução conjugal demanda reorganizações socioemocionais, processuais e estruturais em todos os membros do grupo familiar (LAMELA; FIGUEIREDO, 2016; SILVA; CHAPADEIRO; SILVA, 2020; RAPIZO, 2016). A literatura aponta que no decorrer dos processos de divórcio/dissolução conjugal, os genitores podem apresentar dificuldades em lidar com as novas configurações familiares e em dissociar a parentalidade, que diz respeito às relações construídas entre pais e filhos e que devem ser mantidas após a dissolução conjugal, da conjugalidade que se refere ao relacionamento conjugal estabelecido entre o casal no decorrer de sua união e chegara ao fim após o rompimento do casamento/união estável (GOMES; PEREIRA; RIBEIRO, 2016; ABREU; SILVA; SILVA, 2020; SILVA; CHAPADEIRO; ASSUMPÇÃO, 2019; HAMEINSTER; BARBOSA; WAGNER, 2015; PONCIANO; FÉRES-CARNEIRO, 2017).

No desenrolar dos processos de divórcio/ dissolução conjugal os genitores podem acirrar desavenças que mantinham ainda durante a relação conjugal e, por vezes, envolver os filhos 
em seus embates, o que pode ocasionar novos conflitos, como os de lealdade e alienação parental (CATENACE; SCAPIN, 2018). O conflito de lealdade se instaura quando a criança ou adolescente se alia a um dos pais e imagina que ao se aproximar do outro genitor irá trair ou prejudicar o progenitor que detêm sua lealdade. $\mathrm{O}$ afastamento afetivo entre pais e filhos pode acarretar prejuízos ao desenvolvimento psicossocial das crianças e adolescentes, haja vista a importância da manutenção das relações parentais e a preservação dos vínculos afetivos entre ambos os genitores e seus filhos após a dissolução conjugal (NÜSKE; GRIGORIEFF, 2015).

A lealdade está relacionada com as triangulações que permeiam o sistema familiar e quanto maior o desequilíbrio no triângulo pai-mãe-filho, maior a intensidade dos conflitos de lealdade nos indivíduos (NÜSKE; GRIGORIEFF, 2015; SILVA; CHAPADEIRO, 2019). Cabe ressaltar que as triangulações estão na base de qualquer sistema emocional presente no grupo familiar, ou seja, no momento em que a tensão entre dois membros da família, frequentemente os pais, alcança níveis intensos de ansiedade, uma terceira pessoa, geralmente um filho, é triangulado para reduzir a tensão que se encontra no sistema, o que pode propiciar conflitos, ou não, a depender da dinâmica relacional familiar (BOWEN, 1979).

Nesse sentido, a qualidade da relação coparental, ou seja, a coparentalidade desempenhada pelos genitores para com seus filhos, se configura como um importante aspecto preditor de conflitos de lealdade e particularmente de triangulação dentro de um sistema familiar (SILVA; CHAPADEIRO; SILVA, 2020). A coparentalidade diz respeito à negociação e articulação conjunta dos genitores em coordenar suas responsabilidades no que se refere ao cuidado, formação, desenvolvimento e proteção dos filhos, bem como seus valores, ideais e expectativas de maneira equilibrada (BÖING; CREPALDI, 2016; KOSTULSKI et al., 2017).

Por sua vez, a alienação parental diz respeito à situação em que um dos progenitores, busca se aliar a um filho, munindo-se de estratégias manipuladoras e comportamentos nocivos que visam inibir o contato da criança ou adolescente com o outro genitor, o que pode ocasionar o rompimento do vínculo afetivo do filho com um dos pais (CATENACE; SCAPIN, 2018; GOMES; PEREIRA; RIBEIRO, 2016). Comportamentos alienantes, possuem maiores probabilidades de ocorrer em meio aos processos litigiosos de divórcio e são considerados um tipo de violência praticada contra crianças e adolescentes, podendo acarretar sérias consequências psíquicas e transtornos psicopatológicos nos envolvidos (CATENACE; SCAPIN, 2018; LEITE; OLIVEIRA NETA, 2016).

Cabe ressaltar que, alienação parental e síndrome de alienação parental (SAP) tratam-se de conceitos interligados, porém diferentes. Enquanto a alienação parental diz respeito aos comportamentos alienantes que visam o afastamento do filho de um dos genitores, a síndrome de alienação parental, descrita pela primeira vez em 1980 pelo psiquiatra infantil Richard Gardner, relaciona-se ao conjunto de sinais e sintomas referentes às sequelas emocionais e comportamentais de que vem a padecer os filhos alijados de um dos genitores pelo outro genitor (CATENACE; SCAPIN, 2018; LEITE; OLIVEIRA NETA, 2016).

Ressalta-se a importância de manter uma visão crítica acerca da alienação parental, uma vez que os padrões conflituosos que podem emergir no grupo familiar após o divórcio originam-se de uma complexa teia de interações interpessoais entre os familiares envolvidos. Assim, deve-se haver um aprofundamento na dinâmica relacional e na interação existente entre os indivíduos que compõem o sistema familiar, a fim de evitar enquadrar a família em diagnósticos pautados somente em rotulações individualizantes e em termos que dividem seus membros em vítimas ou culpados (NEGRÃO; GIACOMOZZI, 2015). Nesse sentido, ainda existem questões que devem ser investigadas no que concerne à construção da parentalidade pósdivórcio, com intuito de estimular a coparentalidade e a qualidade dos vínculos e relações familiares após a dissolução conjugal (SILVA; CHAPADEIRO, 2019; SILVA; CHAPADEIRO; SILVA, 2020). 
Diante da complexidade do fenômeno do divórcio na contemporaneidade e suas reverberações no sistema familiar, há a necessidade de superação dos conflitos, ou seja, entendê-los e transformálos em oportunidade de melhoria da qualidade dos relacionamentos pessoais e/ou sociais (BRASIL, 2016; RAPIZO, 2020; SILVA; CHAPADEIRO, 2019; SILVA et al., 2018). Assim, torna-se necessário trabalhar com as demandas advindas do divórcio de modo a contribuir com formas não adversariais de solução de conflitos psicoemocionais, bem como construir intervenções que favoreçam a construção da coparentalidade e a manutenção dos vínculos afetivos entre genitores e seus filhos, fomentando comunicações não violentas e a revisão de posturas nocivas dentro do sistema familiar, uma vez que a literatura tem demostrado que comportamentos alienantes podem culminar na ruptura dos laços familiares e acarretar sérias consequências, principalmente para crianças e adolescentes (BRITO; SILVA, 2017; SILVA; CHAPADEIRO; ASSUMPÇÃO, 2019).

Nesse sentido, em 8 de maio de 2014 o Conselho Nacional de Justiça (CNJ), por meio da Recomendação 050/14, orientou a todos os tribunais do País a adotarem as Oficinas de Parentalidade como política pública de resolução e prevenção de conflitos familiares, disponibilizando o material necessário para implantação em todo o País (BRASIL, 2014). O projeto inicialmente foi desenvolvido pelo Tribunal de Justiça de São Paulo (TJSP), com o apoio e acompanhamento do Conselho Nacional de Justiça e implantado na Comarca de São Vicente, estado de São Paulo, com o nome de Oficina de Pais e Filhos; posteriormente a intervenção passou a ocorrer em diversas outras comarcas do País (BRASIL, 2016).

A literatura aponta que estudos acerca das repercussões da dissolução conjugal no sistema familiar se mostram relevantes e atuais, ressaltando a importância de pesquisas acerca de programas de intervenção voltados às famílias pós-divórcio (SILVA; CHAPADEIRO; ASSUMPÇÃO, 2019; OLIVEIRA; CREPALDI, 2018). Acerca das intervenções voltadas às famílias que vivenciam o divórcio, muitos trabalhos destacam a importância dessas práticas serem constantemente avaliadas e aprimoradas, a fim de oferecer serviços cada vez mais condizentes com as demandas de pais, mães e filhos após a dissolução conjugal (BRITO; SILVA; 2017; SILVA; CHAPADEIRO; 2019; SILVA et al., 2015; SILVA; CHAPADEIRO; SILVA, 2020).

Portanto, este estudo tem por objetivo verificar as avaliações e percepções imediatas decorrentes das intervenções realizadas com os genitores durante o projeto de extensão "Oficinas de Parentalidade", em um município do Triângulo Mineiro, Minas Gerais, Brasil. Ainda, se pretende descrever as expectativas e reflexões da amostra de genitores participantes do projeto acerca das oficinas.

\section{Método}

\section{Tipo de estudo}

Trata-se de uma pesquisa delineada no campo das Ciências Humanas, com caráter observacional descritivo, amparada na abordagem mista (quantiqualitativa), de corte transversal. A pesquisa qualitativa detém interesse em compreender os significados de fenômenos, manifestações, ocorrências, fatos, ideias e assuntos que representam e fornecem molde à vida das pessoas. Esse método faz uso de pressupostos iniciais revistos, conceitos construídos e conhecimentos originais produzidos (TURATO, 2011). Nesse sentido, a pesquisa qualitativa tenta conceber todas as etapas da investigação e da análise como partes do processo social analisado, e também leva em consideração a sua consciência crítica possível (CRESWELL, 2010).

Em relação à pesquisa quantitativa, quando essa não é exclusiva, serve de fundamento ao conhecimento produzido pela pesquisa qualitativa. Tal forma de pesquisa verifica e explica a influência de variáveis preestabelecidas sobre outras variáveis e pode trabalhar em uma relação de complementaridade mútua, sem reduzir os processos metodológicos a limites exclusivamente positivistas (MINAYO, 2011). 


\section{Participantes}

Fizeram parte deste estudo 78 genitores que participaram de alguma das Oficinas de Parentalidade entre junho e dezembro de 2016 em um município do Triângulo Mineiro.

A partir da demanda identificada em um município situado no Triângulo Mineiro, referente às dificuldades encontradas pelas famílias durante os processos de divórcio ou dissolução da união estável, foi implantado um projeto de extensão intitulado "Oficinas de Parentalidade". O projeto constitui-se em uma parceria entre uma universidade do referido município e uma das promotorias da comarca local, tendo início em novembro de 2014; esta é segunda experiência do tipo no estado e a primeira no interior. Em 2014, nas três Varas de Família desta cidade tramitavam cerca de 7.800 processos relacionados a divórcios e eram protocolados cerca de 20 a 30 novos pedidos de divórcios litigiosos mensalmente (SILVA et al., 2015).

O objetivo da intervenção é oferecer suporte às famílias para que possam entender as novas configurações familiares advindas da dissolução conjugal e as repercussões de um divórcio conflituoso para crianças e adolescentes, a fim de auxiliar as famílias a se organizarem e colocarem em prática mudanças eficientes para o bom entendimento familiar. Busca-se, desta forma, instrumentalizar e empoderar pais, mães e filhos, favorecendo um menor dano emocional a todos os envolvidos, por meio de um viés educacional e preventivo (SILVA et al., 2015).

As Oficinas de Parentalidade são coordenadas por uma equipe multiprofissional e acontecem uma vez por mês, aos sábados, em um campus da referida universidade, com duração de quatro horas e contam com público diferente a cada encontro. As Varas de Família da comarca local são responsáveis por convidar, mensalmente, 30 famílias que estejam em processo de divórcio ou dissolução da união estável para a participação nas oficinas. Há uma oficina voltada para crianças de 6 a 11 anos de idade, outra para adolescentes de 12 a 17 anos de idade e duas outras direcionadas aos pais que, por precaução, são alocados em salas diferentes (SILVA et al., 2015).

O perfil socioeconômico dos 78 genitores que participaram do estudo apontou que a idade da amostra é em média de 37 anos, o que indica que os participantes das oficinas são relativamente jovens. $45 \%$ são do sexo masculino e $55 \%$ do sexo feminino; esta equivalência demostra que tanto homens quanto mulheres preocupam-se em buscar novos conhecimentos acerca do divórcio e de suas repercussões. Destes, 28\% declararam escolaridade básica, $50 \%$ escolaridade média e $21 \%$ escolaridade superior, e $1 \%$ declarou pós-graduação, indicando que as oficinas atendem pessoas dos mais diversos graus de instrução.

No que tange ao estado civil, $38 \%$ se declararam casados ou em uma união estável, diferente daquele que os levaram a participar das oficinas, $27 \%$ solteiros, $3 \%$ viúvos e $32 \%$ separados/divorciados. O número de filhos ficou em média 1,7, com idades entre 0 e 17 anos. Tais dados apontam para a heterogeneidade da amostra atendida pelas oficinas e demostram a importância de a intervenção estar preparada para atender tanto pais quanto filhos, sejam crianças ou adolescentes, visto que os genitores possuem filhos de variadas idades.

Os genitores que compuseram a amostra são provenientes de diversas regiões de nosso País (Norte, Nordeste, Sul e Sudeste) e atualmente todos residem com algum familiar no município onde foi realizada a coleta de dados. A profissão dos genitores também se mostrou heterogênea, abrangendo indivíduos com profissões de alta, média e baixa qualificação. A renda familiar variou de 1 a 15 salários mínimos, demostrando, mais uma vez, a heterogeneidade da amostra. No que tange ao tipo de processo no qual os genitores estavam envolvidos, os dados apontaram que $29 \%$ estavam envolvidos em processos de divórcio, 20\% em disputas de guarda, $30 \%$ em processos relacionados à pensão, 19\% em processos relacionados a visitas e $2 \%$ declararam estar envolvidos em outros tipos de processo. Vale ressaltar que $21 \%$ dos genitores encontravam-se envolvidos simultaneamente em mais de um tipo de processo. 


\section{Instrumentos}

Os instrumentos utilizados na coleta dos dados foram: um Questionário Socioeconômico construído pelos pesquisadores e uma Ficha de Avaliação Inicial que consta no material de apoio das oficinas elaborado pelo CNJ. Estes instrumentos caracterizam-se por serem autoaplicáveis e foram preenchidos antes do início das oficinas. O Questionário Socioeconômico abrangeu os seguintes itens: sexo, idade, cidade de origem, estado civil, renda, escolaridade, local de residência, número de filhos e idades, profissão e ocupação atual, renda familiar e tipo de processo. Por sua vez, a Ficha de Avaliação Inicial visou examinar se os participantes já haviam ouvido falar das oficinas, como ficaram sabendo das mesmas, como definem seus relacionamentos com o ex-parceiro e com o(s) filho(s) e o que esperavam das oficinas.

$O$ instrumento utilizado para avaliar o grau de satisfação e a percepção dos pais sobre o trabalho realizado durante as oficinas foi uma Ficha de Avaliação específica para os genitores, que consta no material de apoio das oficinas elaborado pelo CNJ. Esta ficha caracteriza-se por ser autoaplicável e foi preenchida ao final de cada oficina, onde os genitores puderam deixar suas apreciações sobre o trabalho realizado avaliando o método, material, profissionais, espaço e duração, com espaço para sugestões, observações e/ou reclamações. Nela também constam perguntas relativas aos sentimentos e atitudes com relação aos filhos e ao excônjuge, avaliando de forma geral os impactos gerados durante a realização da oficina. Ao final, há um espaço na ficha para que deixem um endereço de e-mail e/ou número de telefone para que possam ser contatados após dois meses a fim de avaliar se a oficina causou alguma consequência na sua vida, na vida dos filhos e do ex-cônjuge.

\section{Procedimentos de coleta de dados}

A coleta se deu nas dependências da universidade, nas salas de aula onde ocorrem as Oficinas de Parentalidade específicas para os genitores. Foram excluídos do estudo genitores que não participaram das Oficinas de Parentalidade no período destacado ou que não aceitaram participar da pesquisa voluntariamente por meio da assinatura do Termo de Consentimento Livre e Esclarecido (TCLE). Os participantes foram abordados e indagados sobre sua vontade de participar da pesquisa antes de iniciarem o preenchimento do Questionário Socioeconômico e da Ficha de Avaliação Inicial, e somente responderam aos instrumentos após assinatura do TCLE. O pesquisador foi previamente treinado para prestar informações necessárias ao preenchimento dos instrumentos e elucidar questões sobre o sigilo e confidencialidade dos dados, em linguagem clara e acessível, utilizandose das estratégias mais apropriadas à cultura, faixa etária, condição socioeconômica e autonomia dos convidados a participar da pesquisa. Para tanto, foi concedido um período de tempo adequado para que os participantes pudessem refletir e, se necessário, consultar o pesquisador. A Ficha de Avaliação Final foi respondida ao término das oficinas, de modo individual e também autoaplicável. Os participantes tiveram tempo livre para preencher os instrumentos iniciais e finais de avaliação, sendo auxiliados pelo pesquisador quando surgia alguma dúvida.

\section{Procedimento de análise de dados}

Os dados socioeconômicos e as questões objetivas referentes às avaliações imediatas frentes às Oficinas de Parentalidade foram descritos em porcentagens. Já os dados qualitativos referentes às percepções da amostra frente às oficinas foram submetidos à técnica de análise de conteúdo. De acordo com Bardin (2009), a análise de conteúdo é caracterizada como um conjunto de técnicas que possibilitam analisar diversos tipos de comunicações. Assim sendo, utiliza procedimentos objetivos e sistemáticos de descrição do conteúdo presente nas mensagens, visando obter indicadores que permitam a inferência de conhecimentos relativos às condições de produção/recepção das mensagens. 


\section{Considerações éticas}

$\mathrm{O}$ projeto que deu origem a este estudo foi aprovado pelo Comitê de Ética em Pesquisa da instituição de origem dos autores (Protocolo $\mathrm{n}^{\circ}$ 52670716.5.0000.5154), e está amparado na Resolução n ${ }^{0}$ 466, de 12/12/2012, do Conselho Nacional de Saúde (CNS).

\section{Resultados e Discussão}

Avaliações imediatas dos genitores acerca da participação nas Oficinas de Parentalidade

As avaliações imediatas dos genitores diante do trabalho realizado nas Oficinas de Parentalidade foram descritas em porcentagens. No que tange ao contexto relacional familiar e às expectativas dos genitores para com as oficinas, os dados indicaram que $28 \%$ já haviam tomado conhecimento da existência desta intervenção e $72 \%$ ainda não conheciam o trabalho. Destes, $67 \%$ souberam das oficinas por meio de audiência, $6 \%$ por amigos, $9 \%$ por alguém que já havia participado e $18 \%$ por outras formas. O número expressivo de participantes que conheceram as oficinas via audiência indica que, muitas vezes, o convite realizado nesse contexto pode ser encarado como uma "intimação" que obriga o comparecimento ou até mesmo como um "castigo" do judiciário aos casais que vivenciam litígios.

No que tange à relação familiar, $11 \%$ da amostra definiram o relacionamento com o excônjuge como "ótimo", 23\% como "bom", 26\% como "regular" e 40\% como "péssimo". No que se refere ao relacionamento mantido com os filhos, 73\% indicaram ser "ótimo", 19\% "bom", 5\% "regular" e 3\% "péssimo". Os pais demostraram ter grande expectativa para com as oficinas sendo esta, na maioria vezes, vista como um meio para solucionar os problemas parentais e conjugais nos quais estão inseridos.

Acerca do trabalho realizado durante as Oficinas de Parentalidade, os dados revelaram que
$73 \%$ dos genitores ficaram "muito satisfeitos", 24\% "satisfeitos" e 3\% assinalaram a alternativa "prefiro não opinar". A respeito do método, $82 \%$ o avaliaram como "muito bom", 17\% como "bom" e $1 \%$ como "regular". Sobre o material, $75 \%$ o avaliaram como "muito bom", 24\% como "bom" e 1\% como "regular". O trabalho dos profissionais foi avaliado por $90 \%$ dos genitores como "muito bom" e por $10 \%$ como "bom". Quanto ao espaço, 74\% o avaliaram como "muito bom" e $26 \%$ como "bom". O tempo de duração das oficinas foi avaliado por $55 \%$ como "muito bom", por $41 \%$ como "bom" e por $4 \%$ como "regular". Ao final, $100 \%$ da amostra sugeriram que indicariam a oficina a alguém e $84 \%$ assinalaram que gostariam de ser contatados novamente após dois meses, deixando um contato.

\section{Percepções imediatas dos genitores frente às Oficinas de Parentalidade}

Os dados qualitativos referentes às percepções imediatas dos genitores frente às Oficinas de Parentalidade foram analisados pela técnica da análise de conteúdo segundo Bardin (2009) e agrupados em três categorias temáticas: Categoria 1 - Impressões gerais frente às Oficinas de Parentalidade; Categoria 2 - O impacto das Oficinas de Parentalidade nas relações parentais: novos caminhos; e 3 - O desafio da efetivação da coparentalidade frente aos resquícios do conflito conjugal.

Categoria 1: Impressões gerais frente às Oficinas de Parentalidade

Esta categoria evidencia as impressões gerais dos genitores frente ao trabalho realizado nas Oficinas de Parentalidade, enfatizando a importância de espaços que propiciem às famílias, envolvidas em processos de divórcio/dissolução conjugal, novos entendimentos acerca das relações familiares após o rompimento conjugal.

A característica educativa/reflexiva das Oficinas de Parentalidade se confirma por meio das observações gerais dos genitores, o que indica que a intervenção pode auxiliá-los no entendimento 
e esclarecimento acerca das relações familiares após o divórcio/dissolução conjugal e na revisão de posturas frente aos filhos e ao ex-cônjuge: "que essa oficina continue para muitos pais entenderem sobre a separação e seus filhos" (Participante 8); "[...] é de suma importância para nós casais que passamos por essa situação" (Participante 9); "acho válida a oficina para melhorar as relações com o ex e com os filhos" (Participante 12); "as oficinas têm bastantes questões esclarecedoras. Parabéns!!!" (Participante 23); “o trabalho é muito produtivo e esclarecedor quanto à relação familiar" (Participante 17); "gostei muito, não conhecia esse trabalho, me ajudou muito e quero a cada momento dar o melhor de mim aos meus filhos" (Participante 29).

A vivência do divórcio pode provocar em todos os familiares, principalmente em pais e filhos, angústias e incertezas que ameaçam a estabilidade emocional, devido às transformações na dinâmica do cotidiano familiar (SILVA et al., 2018). Após a dissolução conjugal muitas mudanças acometem as famílias em processos de reconfiguração e fatores como os arranjos de guarda, visitas, pensão alimentícia e divisão patrimonial movem-se em uma arena permeada por conflitos, principalmente no que tange à relação entre o ex-casal e a construção da parentalidade (LEITE; OLIVEIRA NETA, 2016).

No decorrer das Oficinas de Parentalidade os genitores demonstram insatisfação diante da nova situação familiar, havendo carência de informações acerca de maneiras de lidar com o divórcio e com a frustração pelo fim da relação conjugal, não sendo raros comportamentos destrutivos para com o ex-cônjuge e, também, para com os filhos que podem acabar sendo envolvidos nos embates dos genitores, o que pode acarretar conflitos interparentais e prejudicar a construção da parentalidade nesse período (SILVA et al., 2015; SILVA; CHAPADEIRO; SILVA, 2020).

O conflito interparental é permeado por sentimentos negativos que incluem tristeza e raiva, bem como a presença de diálogos agressivos. Um ambiente familiar estressante pode ocasionar insegurança nos filhos e influenciar negativamente o ajustamento psicológico das crianças e adolescentes (JURAS; COSTA, 2016). Assim, modelos violentos de comunicação devem ser desconstruídos, abrindo margem para formas de linguagem mais pacificadoras denominadas "Comunicações não violentas", caracterizadas por diálogos e reflexões, além de revisões de conceitos, pensamentos e posturas na busca de soluções possíveis para que as necessidades de todos os integrantes da família sejam atendidas, especialmente as dos filhos (BRASIL, 2016).

Os profissionais que atuam em Varas de Família bem sabem o quão angustiante pode ser um processo judicial envolvendo famílias em litígio (SILVA; CHAPADEIRO; SILVA, 2020). As questões que entrelaçam conteúdos de cunho emocional e jurídico podem culminar em diversos conflitos familiares. Sendo que a vivência do divórcio pode acarretar tanto repercussões negativas, quanto positivas aos membros do sistema familiar, a depender da maneira como a família enxerga e administra os desacordos que podem surgir após o rompimento conjugal (SILVA; CHAPADEIRO, 2019; SILVA; CHAPADEIRO; SILVA, 2020).

A literatura ressalta a importância da elaboração de intervenções educativas/reflexivas voltadas à construção e manutenção dos vínculos afetivos e das funções parentais de ambos os genitores e seus filhos após a dissolução conjugal. Por vezes, os genitores carecem de informações que os auxiliem na elaboração de possíveis conflitos advindos do rompimento conjugal e na distinção de parentalidade e conjugalidade, o que dificulta um ambiente familiar saudável para o desenvolvimento das crianças e adolescentes (JURAS; COSTA, 2018; OLIVEIRA; CREPALDI, 2018; RAPIZO, 2020; SILVA et al., 2018; SILVA; CHAPADEIRO; SILVA, 2020).

Assim, as Oficinas de Parentalidade ao fomentar a construção de relações salutares entre pais, mães e filhos, demostram que embora feridos com o processo do divórcio e suas consequências, os pais podem compreender que possuem o poder de determinar o melhor para seus próprios filhos, 
principalmente quando crianças. Assim, ao se empoderarem de suas funções parentais, os genitores podem buscar dentro de si mesmos o real sentido de exercer a parentalidade de maneira colaborativa e de fato saudável, compreendendo a importância da manutenção dos vínculos afetivos para com seus filhos, mesmo na ausência da conjugalidade (ABREU; SILVA; SILVA, 2020).

Portanto, ações como as desenvolvidas nas Oficinas de Parentalidade devem ser estimuladas, uma vez que, de maneira educativa e reflexiva podem auxiliar as famílias a terem acesso a maneiras positivas de enfrentar os conflitos, bem como trazer esclarecimentos aos familiares acerca do complexo momento que vivenciam, o que pode favorecer a diminuição dos conflitos entre os ex-cônjuges e a construção da parentalidade (SILVA et al., 2015; BRITO; SILVA, 2017; SILVA et al., 2018).

Categoria 2: O impacto das Oficinas de Parentalidade nas relações parentais: novos caminhos

Esta categoria traz à baila a dinâmica relacional familiar entre pais e filhos envolvidos em processos de divórcios e/ou dissoluções conjugais e como, por meio das percepções imediatas dos genitores, as Oficinas de Parentalidade puderam auxiliá-los a lidar com estes processos.

Percebe-se na fala dos genitores ao se referirem ao impacto das oficinas na relação com os filhos, reflexões acerca de como seus atos, que muitas vezes passam despercebidos, podem influenciar/ prejudicar seus filhos. Dessa forma, as oficinas caracterizam-se como uma importante ferramenta de aprendizado que possibilita aos genitores vislumbrar novos caminhos para com a conduta que mantinham com os filhos, como fora evidenciado nas seguintes falas: "[...] ajudou muito, por mais que saibamos quão importante é nossa ajuda para com o filho, a oficina nos ajuda a ver com uma forma diferente" (Participante 2); "[...] foi possivel pontuar situações em que não me comportei da maneira correta. Com certeza pensarei melhor de agora em diante antes de tomar certas atitudes"
(Participante 6); "[...] ajudou a abrir mais a mente dos pais que o mais importante na separação são os filhos. Para os pais não serem egoístas" (Participante 9); "nos faz refletir as nossas ações e como essas ações são recebidas pelos filhos" (Participante 12); "[...] como tratar a criança e a ex para ter um convivio melhor" (Participante 16); "meu filho precisa de mais atenção do que o momento vivido durante o processo" (Participante 18); "ajudou a compreender melhor os sentimentos de minha filha em relação ao término do matrimônio" (Participante 33); "[...] pois me mostrou a importância que minha filha pode dar à presença do pai" (Participante 35); "muito me esclareceu sobre várias questões importantes, como, por exemplo, a alienação parental e como trabalhar de modo mais efetivo para que ela não ocorra" (Participante 59); "[...] e muito, eu não sabia o quanto a separação mexia com os nossos filhos, tinha noção, mas não tanto assim" (Participante 60).

Nesse sentido, é necessário que a experiência do divórcio seja vivida pelo ex-casal que a enfrenta de forma equilibrada, com maturidade e respeito, para que os filhos sejam protegidos de consequências emocionais que podem causar danos ao desenvolvimento emocional (MOTA, 2016; RAPIZO, 2016; SILVA et al., 2015; SILVA et al., 2018; SILVA; CHAPADEIRO; ASSUMPÇÃO, 2019). A família é para as crianças a primeira e principal fonte de apoio social, auxiliando-as a reconhecer o mundo, sendo que um divórcio conflituoso pode fomentar sentimentos como raiva, tristeza, medo do abandono e culpa frente à nova configuração familiar advinda da dissolução conjugal (ABREU; SILVA; SILVA, 2020). Já para o adolescente, a família é o alicerce que o respalda no desenvolvimento de seus interesses e habilidades diante transformações físicas e psicológicas características desta fase, sendo que a ruptura dos laços afetivos com os genitores após a dissolução conjugal pode gerar repercussões nocivas à sua capacidade adaptativa, autonomia e confiança para lidar com as desafios inerentes a adolescência (MOTA, 2016). 
Assim, a experiência do divórcio para os filhos depende em larga medida de como os genitores compartilham suas funções parentais, ou seja, exercem a coparentalidade e conduzem suas divergências relacionadas à conjugalidade que se findou (SILVA; CHAPADEIRO; ASSUMPÇÃO, 2019). Sendo que, caso sejam instauradas dinâmicas relacionais conflituosas no sistema familiar após a dissolução conjugal, como alienação parental, conflitos de lealdade, ações violentas e/ou abandono afetivo, a família pode passar a utilizálas como modo padrão de comunicação, deixando de resolver os conflitos prementes, o que pode fomentar o surgimento de novos conflitos e produzir prejuízos ao desenvolvimento de crianças e adolescentes. Percebe-se, então, a relevância de ações que estimulem o exercício da coparentalidade pelos genitores e que promovam reflexões acerca de suas condutas para com os ex-cônjuges e seus filhos (BRITO; SILVA, 2017; SILVA; CHAPADEIRO, 2019).

No que tange aos impactos e significados da participação nas Oficinas de Parentalidade nas vidas dos genitores, percebe-se que a intervenção funciona como forma de empoderá-los sobre suas atitudes e comportamentos diante dos ex-cônjuges e dos filhos, promovendo reflexões acerca de relações familiares mais saudáveis e menos adversariais. O empoderamento dos participantes pode ser evidenciado nas seguintes falas: "uma chance de paz com minha ex-parceira" (Participante 2); "uma nova visão com relação à convivência com nossos filhos. Tenho conhecimento que já tive atitudes erradas e quero melhorar nesse sentido" (Participante 6); "melhora na forma de como lidar com situações adversas. Tentar e fazer o que o ex não puder para não prejudicar a filha. Evitar debates, comentários sobre a ex e problemas para minha filha" (Participante 7); "[...] a refletir e pensar nos meus filhos e não só em briga com meu ex-marido" (Participante..9); "serviu como uma referência positiva na minha maneira de entender esse momento de separação" (Participante 24); "muito na minha vida, mostrou algumas coisas que não queria ver" (Participante 27);
"[...] me deu mais ânimo para a vida e sair dessa depressão e enxergar as coisas de forma mais abrangente" (Participante 29); "[...] me mostrou a como lidar com o divórcio" (Participante 36); "significou que é possivel resolver problemas através do diálogo" (Participante 42).

O empoderamento significa capacitar os participantes das oficinas para que aprendam a resolver seus conflitos de forma sensata, potencializando ações, comunicações não violentas e reflexões acerca de suas próprias atitudes, para com os filhos e com o ex-parceiro, sendo que um dos princípios das Oficinas de Parentalidade é auxiliá-los nessa tarefa (BRASIL, 2016).

Sabe-se que divórcios e dissoluções conjugais implicam diversos desafios, seja na clínica ou na esfera jurídica, sendo a qualidade das vivências entre pais e filhos um determinante fator na intensidade dos efeitos do fim do relacionamento conjugal. Maneiras nocivas de gerenciar os conflitos por parte dos genitores, principalmente quando há grande litigiosidade, podem acarretar um forte abalo emocional para todos os envolvidos (NÜSKE; GRIGORIEFF, 2015). O rompimento conjugal, quando mal conduzido, pode desagregar toda a família e extinguir para os filhos a possibilidade de futuras aproximações, seja por medo de que o outro genitor também vá embora, ou por sentirem que adultos não são honestos nem confiáveis. Portanto, uma ajuda especializada de operadores jurídicos e não jurídicos não é apenas bem-vinda, mas também crucial para a retomada do ciclo de crescimento das famílias de modo menos danoso (SILVA et al., 2015).

Sendo assim, a partir do entendimento de como a experiência do divórcio/dissoluções conjugais e os conflitos que emergem destes impactam os envolvidos e repercutem no sistema familiar como um todo, é possível que os genitores enxerguem novas maneiras de mediar as questões que enfrentam, tentando melhorar a relação com os exparceiros, o que pode reverberar em um ambiente familiar mais saudável para as crianças e adolescentes. Nesse sentido, as Oficinas de Parentalidade despontam como uma importante ferramenta de 
reflexão que pode auxiliar nas relações familiares, abrindo novos caminhos para o bem-estar dos genitores e, principalmente, dos filhos (SILVA et al., 2015; SILVA; CHAPADEIRO; SILVA, 2020).

Categoria 3: O desafio da efetivação da coparentalidade frente aos resquícios do conflito conjugal

Nesta categoria emergem questões relacionadas à dinâmica relacional exercida pelo ex-casal após o rompimento conjugal, enfatizando como os resquícios dos conflitos conjugais podem reverberar na efetivação da coparentalidade e, também, como as Oficinas de Parentalidade enquanto instrumento de pacificação e reflexão, repercutem na dissociação entre conjugalidade e parentalidade.

No que tange à relação com o ex-cônjuge, percebe-se que mesmo com auxílio das oficinas parentalidade, alguns genitores apresentam dificuldades em dissociar a parentalidade da conjugalidade, se mantendo presos os resquícios do conflito conjugal, atribuindo ao outro progenitor a culpa pelos conflitos que permeiam o sistema familiar, bem como suas angústias e frustrações, o que poder dificultar a construção da coparentalidade, como pode ser evidenciado nas seguintes falas: "[...], a pessoa quem causa todo o conflito em família é minha ex" (Participante 8); “[...] ter calma e fazer minha parte mesmo que o outro não faça a sua" (Participante 9); "na verdade espero que tenha o ajudado a refletir sobre como agir comigo e com as crianças" (Participante 11); "não, porque não temos contato" (Participante 36); "ajudou, mas mesmo assim ela é uma pessoa dificil, vou fazer minha parte" (Participante 41); "ah, mais ou menos, tenho muita mágoa dele, ele que amava muito nossas filhas, se distanciou muito, ele é quem mais precisava dessa reunião, porém não veio!!!" (Participante 60).

O grupo familiar é fundado a partir de um casal, que traz consigo o peso das influências e desejos das gerações que os precederam, sendo um local de transmissão de influências, tanto biológicas quanto psicológicas, que se mantêm por meio da rotina, das regras e dos rituais que caracterizam cada família (PONCIANO; FÉRES-CARNEIRO, 2017). Sendo que, a conjugalidade é permeada por mitos e quando os casais constatam a discrepância entre suas expectativas e a realidade da vida a dois, a decepção é tamanha que se inicia um processo no qual um tende a culpabilizar o outro pelas frustrações da união que fugira da idealizada (WAGNER; MOSMANN, 2013). Entretanto, os impasses que permeiam o sistema familiar após o rompimento conjugal envolvem aspectos relacionais, contextuais e pessoais, que de maneira circular se entrelaçam e interatuam recursivamente um sobre o outro, o que impossibilita explicações lineares e unicausais que responsabilizem um ou outro membro do sistema familiar pelos conflitos que podem ocorrer no decorrer dos processos de divórcio (OLIVEIRA; CREPALDI; 2018).

Nos casais envolvidos em processos de divórcio/dissolução conjugal, são comuns sentimentos de mágoa, frustração, decepção, ódio e vingança, que vão muito além do puro desejo de findar o relacionamento conjugal. Os ex-cônjuges tendem a buscar devastar uns aos outros, seja por meio de represálias materiais ou mesmo emocionais. Para tanto, por vezes, os filhos podem ser usados como escudo ou armas, sendo arrastados para dentro do campo de batalha dos pais (SILVA et al., 2015) Portanto, diferenciar a conjugalidade, que se trata da relação dos indivíduos enquanto casal, da parentalidade, que tem a ver com a relação dos genitores para com seus filhos, torna-se fundamental para o bem-estar dos filhos e para a efetivação da coparentalidade pós-divórcio (SILVA; CHAPADEIRO; SILVA, 2020).

De acordo com a teoria familiar sistêmica, a relação coparental pode ser entendida como um subsistema autônomo, no mínimo triádico, composto por ambos os genitores e seus filhos crianças e/ou adolescentes e, que, exerce influência e reverbera no desenvolvimento dos filhos e no grupo familiar em sua totalidade. Nesse sentido, torna-se importante que os genitores busquem a efetivação da coparentalidade, ou seja, o envolvimento compartilhado e recíproco nos cuidados prestados aos 
filhos, independentemente de seus laços relacionais que possuem com outro progenitor (BÖING; CREPALDI, 2016).

Contudo, nem todos os genitores conseguem dissociar a conjugalidade da parentalidade e minimizar os conflitos advindos do rompimento conjugal, o que prejudica a coparentalidade e pode vir a repercutir negativamente na manutenção dos vínculos parentais entre pais e filhos após a dissolução conjugal (KOSTULSKI et al., 2017). A distinção entre conjugalidade e parentalidade é um desafio para o exercício da parentalidade; por vezes, os genitores, mesmo que não intencionalmente, envolvem os filhos em suas disputas, o que pode propiciar conflitos de lealdade e práticas alienantes, dificultando a construção da coparentalidade e a continuidade das relações parentais (SILVA; CHAPADEIRO; ASSUMPÇÃO, 2019; SILVA; CHAPADEIRO; SILVA; 2020). Assim, ações com pais e mães no sentido de minorar os resquícios do conflito conjugal e estimular a relação coparental visando a preservação dos vínculos afetivos entre os genitores e seus filhos devem ser estimuladas (KOSTULSKI et al., 2017).

Nesse sentido, as Oficinas de Parentalidade são desenvolvidas com o intuito de promover, por meio de estratégias de empoderamento, instrumentalização e responsabilização, reflexões acerca da "cultura da paz" e reduzir a litigiosidade que permeia a sociedade, buscando auxiliar os genitores a resolver adequadamente seus conflitos e entender a importância da participação de ambos no cotidiano dos filhos, para que assim possam ajudá-los no trato para com a nova configuração familiar e perseverar o desenvolvimento emocional saudável das crianças e adolescentes após a dissolução conjugal (BRASIL, 2016).

Tais características das Oficinas de Parentalidade se mostram presentes nas falas da maioria dos genitores que conseguiram se colocar no lugar do outro e deixar lado seus conflitos, expandindo o olhar sobre a relação com o ex-cônjuge, demonstrando perceber que a maneira como conduzem suas relações podem afetar os filhos, dissociando a parentalidade da conjugalidade, como visto nas seguintes falas: "sim, posso rever o que ele poderia estar pensando sobre a situação vivida" (Participante 3); "[...] tínhamos bastantes conflitos perante nosso filho, depois das oficinas vamos mudar nossos modos" (Participante 10); "ajuda a entender melhor as ações do outro, se colocar no lugar do outro" (Participante 12); "[...] vou buscar falar e utilizar outros métodos para buscar o que realmente precisam meus filhos" (Participante 17); "[...] mostraram que as duas partes envolvidas devem se conscientizar na melhor forma de cuidar desse assunto" (Participante 24); "devemos ter uma relação cordial em beneficio da nossa filha" (Participante 33); "agora sei que eu e meu ex podemos ter uma boa convivência" (Participante 42); "eu tenho que me policiar mais e ter uma mente mais aberta, escutar mais e me colocar no lugar do ex" (Participante 55).

Sabe-se que, o divórcio em si não é o causador de danos aos membros da família, pois também seria prejudicial se os genitores adiassem o rompimento conjugal e mantivessem relacionamentos familiares violentos e não saudáveis ao desenvolvimento dos filhos. Contudo, o divórcio é mais bem compreendido pelos filhos quando os pais sabem conduzi-lo de maneira saudável e, quando bem administrada, a dissolução conjugal pode até ser encarada de forma positiva, pois os filhos aprenderão a se adaptar mais cedo às situações de perdas que porventura surgirão no decorrer de suas vidas (HAMEISTER; BARBOSA; WAGNER, 2015; MOTA, 2016).

De imediato, a conscientização da família em fase pós-rompimento conjugal caracteriza-se como a maior vantagem de se participar das Oficinas de Parentalidade, pois, embora seja uma fase delicada, esta pode ser vivenciada de uma forma menos agressiva e que preze pela manutenção dos vínculos familiares, possibilitando aos filhos o direito de conviver com ambos os genitores em igualdade de condições (SILVA et al., 2015). Nesse sentido, no decorrer dos processos de divórcio, principalmente em casos litigiosos, deve-se haver um grande esforço dos genitores para se adaptarem às mudanças advindas da dissolução conjugal 
e preservar os vínculos parentais. Assim, a diferenciação entre conjugalidade e parentalidade é de suma importância para os pais superarem seus conflitos e exercerem de fato a coparentalidade, o que pode vir a beneficiar o desenvolvimento saudável dos filhos (SILVA; CHAPADEIRO; SILVA, 2020).

Ao promover reflexões acerca de relações familiares mais saudáveis, vislumbra-se que as Oficinas de Parentalidade, podem, também, auxiliar o judiciário na conciliação e mediação de acordos com famílias pós-divórcio. No entanto, até o momento não foi possível elaborar estatisticamente o índice de conflitos solucionados judicialmente pelos participantes das oficinas, o que demanda mais estudos acerca das Oficinas de Parentalidade e suas reverberações no cotidiano de seus participantes, uma vez que espera-se que muitos ex-casais que passaram pela intervenção cheguem às audiências com novos conceitos absorvidos por essa experiência (SILVA et al., 2015).

No mais, práticas grupais necessitam de uma constante análise crítica acerca de suas potencialidades e limitações, cabendo ao profissional reconhecer a subjetividade do grupo e se manter em permanente atualização para que as demandas sejam trabalhadas de forma eficaz (RASERA; ROCHA, 2010). Sendo assim, observando as percepções imediatas dos genitores acerca da relação com o ex-cônjuge, podemos perceber que, de imediato, nem todos conseguem atingir o nível de empoderamento que as oficinas buscam proporcionar. Muitos ex-casais encontram-se presos no conflito conjugal, o que pode ser negativo para as relações parentais e dificultar a efetivação da coparentalidade, o que fomenta discussões acerca de como as oficinas atingem seus participantes a longo prazo, fazendo-se necessários estudos longitudinais acerca das repercussões das Oficinas de Parentalidade no funcionamento familiar.

\section{Considerações finais}

Percebe-se que na contemporaneidade a família vem sofrendo transformações em suas configurações e dinâmicas relacionais e, principalmente, após processos de divórcio/dissolução de uniões estáveis os membros do sistema familiar podem apresentar grandes dificuldades em lidar com as novas configurações familiares advindas do rompimento conjugal e que diferem do modelo ideológico patriarcal que ainda é dominante em nossa sociedade. Nesse sentido, o estudo permite suscitar a importância de práticas educativas/reflexivas, como as oferecidas pelas Oficinas de Parentalidade, que buscam empoderar seus participantes acerca de comportamentos alienantes exercidos, muitas vezes, por eles próprios, e que podem ser danosos para todos os membros da família, principalmente para as crianças e adolescentes.

Enquanto um instrumento que visa promover a "cultura da paz" e disseminar conhecimentos acerca de como lidar com as mudanças familiares provenientes de divórcios/dissoluções conjugais, as Oficinas de Parentalidade realizadas no referido município demostraram, por meio deste estudo, atender genitores com características socioeconômicas heterogêneas, o que salienta sua eficácia independente da classe social ou do nível de instrução/qualificação de seus participantes.

Os genitores que compuseram o estudo demonstraram alto nível de reflexão e empoderamento, principalmente ao se referirem às atitudes para com os filhos. Tornou-se evidente que, muitas vezes, os genitores se prendem tanto aos conflitos conjugais que não percebem que estão utilizando os próprios filhos como meio de punir os ex-parceiros. Sendo assim, as oficinas abrem novos caminhos para que os genitores possam pensar sobre suas relações parentais e diferenciem conjugalidade de parentalidade, beneficiando a si próprios e aos filhos.

Contudo, pôde se constatar que, enquanto a maioria dos genitores reflete sobre formas mais saudáveis de se relacionar com os ex-parceiros em beneficio dos filhos e reconhecem a necessidade de mudanças em seus comportamentos que outrora vinham sendo destrutivos, alguns não conseguem apreender de imediato os conteúdos ministrados nas Oficinas de Parentalidade, atribuindo ao ex-cônjuge a culpa pelos conflitos familiares 
presentes no sistema familiar, fato que pode vir a ser negativo para as relações parentais e para a efetivação da coparentalidade. Torna-se necessário, então, a produção de estudos longitudinais acerca das repercussões das Oficinas de Parentalidade no funcionamento familiar, buscando entender como a intervenção ecoa em seus participantes a médio e longo prazo.

Os dados encontrados neste estudo evidenciam que a Oficina de Parentalidade, na opinião dos participantes, constituíram-se como importante espaço de reflexão, auxiliando-os a melhorar suas relações familiares, ainda que o conflito conjugal e a culpabilização do ex-parceiro continuem preponderando para alguns genitores. Cabe ressaltar que este trabalho não teve o intuito de esgotar o conhecimento no que se refere à temática e teve como limitação a análise exclusivamente das avaliações e percepções imediatas dos genitores que participaram das Oficinas de Parentalidade. Assim, recomenda-se que futuros estudos englobem, também, a percepção dos filhos para que seja possível um maior conhecimento acerca da vivência do divórcio e das reverberações das Oficinas de $\mathrm{Pa}$ rentalidade nas relações familiares.

Diante da complexidade das relações familiares pós-divórcio, o trabalho com famílias nas Oficinas de Parentalidade apresenta questões desafiadoras aos profissionais. Por vezes os genitores se encontram em um momento tenso e desgastante, apresentando atitudes hostis para com a equipe e/ ou levando aos profissionais demandas demasiadamente pessoais e jurídicas, o que pode acarretar sentimentos de incapacidade e angústias na equipe. Assim, seria oportuno que estudos futuros se debrucem, também, em buscar instrumentos que fomentem a formação contínua dos profissionais que atuam em Oficinas de Parentalidade.

Sugere-se, também, a elaboração de pesquisas que busquem conhecer onde e como ocorrem as oficinas voltadas para pais e filhos no Brasil, uma vez que é sabido que as intervenções são promovidas em diversas comarcas do território nacional, como preconiza a Recomendação 050/14 do Conselho Nacional de Justiça. Contudo, ainda existem poucos trabalhos que buscam descrever o funcionamento da intervenção em cada região, o que dificulta uma visão mais ampla da ação e dos resultados que produz em prol das famílias pósdivórcio.

Logo, estudos que abarquem as Oficinas de Parentalidade, bem como outras intervenções que ocorrem a favor das famílias pós-divórcio devem ser estimulados, uma vez que práticas grupais devem se manter em constante construção, para que sempre tragam resultados positivos e condizentes com as necessidades da comunidade. No mais, as Oficinas de Parentalidade despontam como uma importante política pública de auxílio às famílias, evidenciando que o divórcio e as dissoluções conjugais não devem significar o fim das relações familiares, mas sim recomeços.

\section{Referências}

ABREU, C. D.; SILVA, L. D. L.; SILVA, L. M. Divórcio dos pais: sentimentos e percepções das crianças. Semina: Ciências Sociais e Humanas, Londrina, Londrina, v. 41, n. 1, p. 19-32, 2020. Doi: https://doi.org/10.5433/1679-0383.2020v41n1p19. Disponível em: https://bit.ly/3sXUaBo. Acesso em: 29 jun. 2020.

BARDIN, L. Análise de conteúdo. Lisboa: Edições 70, 2009.

BOWEN, M. De la familia al individuo: la diferenciación del sí mismo em el sistema familiar. Barcelona: Paidos, 1979.

BÖING, E.; CREPALDI, M.A. Relação pais e filhos: compreendendo o interjogo das relações parentais e coparentais. Educar em Revista, Curitiba, n. 59, p. 17-33, 2016. Doi: https://doi.org/10.1590/01044060.44615. Disponível em: https://bit.ly/3uqofdk. Acesso em: 30 jun. 2020.

BRASIL. Ministério da Justiça. Conselho Nacional de Justiça. Oficina de pais e filhos: cartilha do instrutor: cartilha do instrutor. Brasília: CNJ, 2016. Disponível em: https://bit.ly/2WDLbYD. Acesso em: 29 jun. 2020. 
BRASIL. Ministério da Justiça. Conselho Nacional de Justiça. Recomendação N. 50, de 08 de maio de 2014. Brasília: CNJ, 2014. Disponível em: https:// bit.ly/2RcFYqp. Acesso em 29 jun. 2020.

BRITO, M. M.; SILVA, A. A. B. A mediação familiar e o fim do relacionamento conjugal: o problema do acesso à justiça e a experiência das oficinas de parentalidade. Revista de Formas Consensuais de Solução de Conflitos, Florianópolis, v. 3, n. 2, p. 1936, 2017. Disponível em: https://bit.ly/3cQYFbr. Acesso em: 15 jan. 2020.

CANO, D. S.; GABARRA, L. M.; MORÉ, C. O.; CREPALDI, M. A. As transições familiares do divórcio ao recasamento no contexto brasileiro. Psicologia: Reflexão e Crítica, Porto Alegre, v. 22, n. 2, p. 214-222, 2009. Doi: http://dx.doi.org/10.1590/ S0102-79722009000200007. Disponível em: https://bit.ly/2PI5GCL. Acesso em: 15 jan. 2020.

CATENACE, R. V.; SCAPIN, A. L. Síndrome da alienação parental: efeitos psicológicos gerados na tríade familiar pela síndrome da alienação parental. Revista Uningá Review, Maringá, v. 28, n. 1, p. 7077, 2018. Disponível em: https://bit.ly/2Pxr6m9. Acesso em: 15 jan. 2020.

CRESWELL, J. W. Projeto de pesquisa métodos qualitativo, quantitativo e misto. Porto Alegre: Artmed, 2010.

GOMES, M. F. M.; PEREIRA, M. V. C.; RIBEIRO, E. J. Alienação Parental: Quando pais e crianças necessitam de ajuda. Millenium-Journal of Education, Technologies, and Health, Lisboa, n. 50, p. 283-291, 2016. Disponível em: https://bit. ly/3mmH1j4. Acesso em: 15 jan. 2020.

HAMEISTER, B. D. R.; BARBOSA, P. V.; WAGNER, A. Conjugalidade e parentalidade: uma revisão sistemática do efeito spillover. Arquivos Brasileiros de Psicologia, Rio de Janeiro, v. 67, n. 2, p. 140-155, 2015. Disponível em: https://bit. ly/324Xq2p. Acesso em: 15 jan. 2020.

JURAS, M. M.; COSTA, L. F. Não foi bom pai nem bom marido: conjugalidade e parentalidade em famílias separadas de baixa renda. Psicologia: Teoria e Pesquisa, Brasília, v. 32, n. 5, p. 1-9, 2016. Doi: http://dx.doi.org/10.1590/0102-3772e32ne215. Disponível em: https://bit.ly/3cV6PQ1. Acesso em: 15 jan. 2020.
JURAS, M. M.; COSTA, L. F. Uma proposta de atendimento psicossocial grupal com pais e mães separados. Interação em Psicologia, Curitiba, v. 22, n. 2, p. 133-138, 2018. Doi: http://dx.doi. org/10.5380/psi.v22i2.53252. Disponível em: https://bit.ly/3utwLrW. Acesso em: 15 jan. 2020.

KOSTUlSKI, C. A.; CHRISTOFARI, G. C.; BlOSS, G. M.; PARABONI, D. M. A. Coparentalidade em famílias pós-divórcio: uma ação desenvolvida em um núcleo de práticas judiciárias. Pensando Famílias, Porto Alegre, v. 21, n. 2, p. 105-117, 2017. Disponível em: https:// bit.ly/3wzXIS4. Acesso em 29 Jun. 2020.

LAMELA, D; FIGUEIREDO, B. Coparenting after marital dissolution and children's mental health: a systematic review. Jornal de Pediatria, Porto Alegre, v. 92, n. 4, p. 331-342, 2016. Disponível em: https://bit.ly/3sZVrbs. Acesso em 15 Jun. 2020. https://doi.org/10.1016/j.jped.2015.09.011

LEITE, D. E. M.; OLIVEIRA NETA, M. R. Síndrome da alienação parental-SAP: O Resultado de uma guerra familiar. Direito \& Realidade, Monte Carmelo, v. 4, n. 2, p. 46-71, 2016. Disponível em: https://bit.ly/3wAk00u. Acesso em: 15 jan. 2020.

MENDES, J. A. A.; BUCHER-MALUSCHKE, J. S. N. F.; VASCONCELOS, D. F.; SOUZA, G. G.; COSTA, P. V. M. N. Perspectiva sistêmica: um olhar necessário para atuação dos atores jurídicos junto à disputa de guarda. Nova Perspectiva Sistêmica, São Paulo, v. 25, n. 54, p. 88-104, 2016. Disponível em: https://bit.ly/3dCPDy5. Acesso em: 15 jan. 2020.

MINAYO, M. C. Pesquisa social: teoria, método e criatividade. Petrópolis: Vozes, 2011.

MINUCHIN, P.; COLAPINTO, J.; MINUCHIN, S. Trabalhando com famílias pobres. Artmed, 1999.

MINUCHIN, P.; COLAPINTO, J.; MINUCHIN, S. O desafio de trabalhar com famílias de alto risco social: uma abordagem sistêmica. São Paulo: Roca, 2011.

MOTA, C. P. Individuação e coping em adolescentes de famílias tradicionais e divorciadas. Temas em Psicologia, Ribeirão Preto, v. 24, n. 3, p. 11151128, 2016. Disponível em: https://bit.ly/3fUtH3Y. Acesso em: 15 jan. 2020. 
NEGRÃO, N. T.; GIACOMOZZI, A. I. A separação e disputa de guarda conflitiva e os prejuízos para os filhos. Liberabit, Lima, Perú, v. 21, n. 1, p. 103114, 2015. Disponível em: https://bit.ly/3mnGI7D. Acesso em: 29 jun. 2020.

NÜSKE, J. P. F.; GRIGORIEFF, A. G. Alienação parental: complexidades despertadas no âmbito familiar. Pensando Famílias, Porto Alegre, v. 19, n. 1, p. 77-87, 2015. Disponível em: https://bit. ly/3wGsF1R. Acesso em: 15 jan. 2020.

OLIVEIRA, J. L. A. P.; CREPALDI, M. A. Relação entre o pai e os filhos após o divórcio: revisão integrativa da literatura. Actualidades en Psicología, San José, Costa Rica, v. 32, n. 124, p. 92-110, 2018. Disponível em: https://bit.ly/2Q2A4aA. Acesso em: 15 jan. 2020. http://dx.doi.org/10.15517/ ap.v32i124.29021

PONCIANO, E. L. T.; FÉRES-CARNEIRO, T. Conjugalidade, parentalidade e separação: repercussões no relacionamento pais e filhos(as). Psicologia em Estudo, Maringá, v. 22, n. 2, p. 277-287, 2017. Doi: https://doi.org/10.4025/ psicolestud.v22i2.32808. Disponível em: https:// bit.ly/2OqZaj3. Acesso em: 15 jan. 2020.

RAPIZO, R. Entre laços e nós: conversando sobre divórcio. Curitiba: Appris, 2020.

RAPIZO, R. Espaço de conversas sobre o divórcio: a diferença de posicionamento como recurso para transformação. Nova Perspectiva Sistêmica, São Paulo, v. 23, n. 50, p. 32-50, 2016. Disponível em: https://bit.ly/39NBSLX. Acesso em: 15 jan. 2020.

RASERA, E. F.; ROCHA, R. M. G. Sentidos sobre a prática grupal no contexto de saúde pública. Psicologia em Estudo, Maringá, v. 15, n. 1, p. 35-44, 2010. Disponível em: https://bit. ly/3uty5eo. Doi: http://dx.doi.org/10.1590/S141373722010000100005 . Acesso em: 15 jan. 2020.

SILVA, L. M.; ARAGÃO, A. S.; SILVA, L. C. C. M.; JULIÃO, C. H.; LAVOR, M. D. D.; CHAGAS, L. M. O.; LIMA, A. J.; TERASSI, G.; MATA, J. J.; SILVA, L. D. L.; GOMES, L. C. S. Oficinas de Parentalidade. Participação, Brasília, n. 27, p. 1826, 2015. Disponível em: https://bit.ly/2PxsQfb. Acesso em: 15 jan. 2020.
SILVA, L. D. L.; CHAPADEIRO. C. A. Rupturas e permanências o divórcio e suas reverberações na construção da parentalidade. 2019. Dissertação (Mestrado em Psicologia) - Universidade Federal do Triângulo Mineiro, Uberaba, 2019.

SILVA, L. D. L.; CHAPADEIRO, C. A.; ASSUMPÇÃO, M. C. O exercício da parentalidade após a dissolução conjugal: uma revisão integrativa. Pensando Famílias, Porto Alegre, v. 23, n. 1, p. 105 120, 2019. Disponível em: https://bit.ly/3wuCbVw. Acesso em: 15 jan. 2020.

SILVA, L. D. L.; CHAPADEIRO, C. A.; SILVA, L. M. A construção da parentalidade após a dissolução conjugal e as oficinas de parentalidade. Nova Perspectiva Sistêmica, São Paulo, v. 29, n. 66, p. 87-100, 2020. Doi: https://doi.org/10.38034/nps. v29i66.519. Disponível em: https://bit.ly/31Ts5PO. Acesso em: 29 jun. 2020.

SILVA, L. O.; OLIVEIRA, L. R. R. C.; SOARES, L. C. E. C.; RAPIZO, R. L. Diálogos com pais e mães separados: grupos reflexivos no sistema de justiça. Nova Perspectiva Sistêmica, São Paulo, v. 27, n. 62, p. 88-108, 2018. Doi: http:// dx.doi.org/10.21452/2594-43632018v27n62a06. Disponível em: https://bit.ly/3moZtay. Acesso em: 15 jan. 2020.

TURATO, E. R. Tratado da metodologia da pesquisa clínico-qualitativa. 3. ed. Petrópolis: Vozes, 2011.

WAGNER, A.; MOSMANN, C. Intervenções na conjugalidade: estratégias de resolução dos conflitos conjugais. In: BAPTISTA, M. N.; TEODORO, M. L. M. (Org.). Psicologia de família teoria, avaliação e intervenção. Porto Alegre: Artmed, 2013. p. 240-248.

Recebido em: 5 maio 2020

Aceito em: 23 jul. 2020 